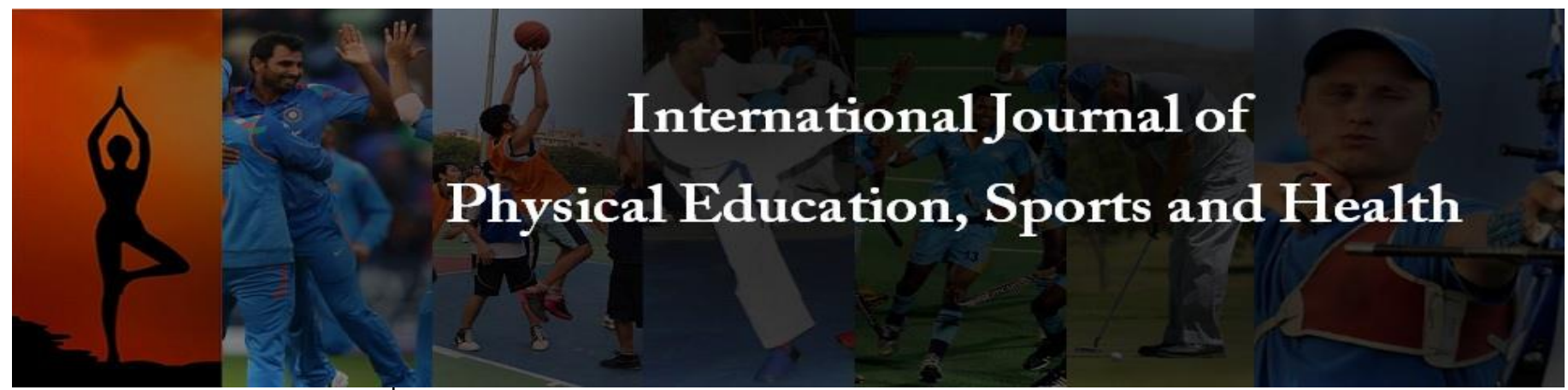

P-ISSN: 2394-1685

E-ISSN: 2394-1693

Impact Factor (ISRA): 5.38

IJPESH 2020; 7(5): 31-32

(C) 2020 IJPESH

www.kheljournal.com

Received: 12-07-2020

Accepted: 06-09-2020

Brijesh Kumar Yadav

Nagrik P.G. College, Janghai,

Jaunpur, Uttar Pradesh, India

Dr. Ramesh Chand Yadav

LNIPE, NERC, Sonapur,

Guwahati, Assam, India
Corresponding Author: Dr. Ramesh Chand Yadav LNIPE, NERC, Sonapur, Guwahati, Assam, India

\section{Relationship of competitive sports anxiety and selected motor variables with the cricket performance}

\author{
Brijesh Kumar Yadav and Dr. Ramesh Chand Yadav
}

DOI: https://doi.org/10.22271/kheljournal.2020.v7.i5a.1824

\section{Abstract}

The aim of the present study was to investigate the relationship of competitive sports anxiety and selected motor variables with the cricket performance. Forty cricket male batsmen randomly selected from the East Zone Intervarsity Tournament 2017 -18 organized by VBSP University, Jaunpur (UP). Pearson Product moment correlation was applied on the data. Result of the study were muscular strength $(0.421)$, flexibility $(0.514)$, agility $(0.431)$, reaction time $(-0.517)$, somatic anxiety $(-0.458)$, cognitive anxiety $(-$ $0.539)$, self - confidence $(0.571)$ were significantly correlated with the cricket performance. Muscular endurance $(0.213)$ and speed $(-0.126)$ were not have the relationship with the cricket performance. Anxiety could influenced the muscular strength, flexibility, agility and reaction time of the cricketers.

Keywords: Cricket, anxiety, performance

\section{Introduction}

It is important to note that sport-related anxiety is considered to be an unpleasant response generally associated with the stress of participating in sport. Traditionally, sport performance as a concept has included participation in activities that relate to regular practice and competition of ones' sport; however, more recently, this has also included performance in activities that relate to sport injury prevention, rehabilitation, and the return to sport process (Brewer BW, Redmond C, 2016) ${ }^{[1]}$.

Anxiety is characterized as apprehension about performance, lack of concentration, and distraction during competition. On the other hand, somatic anxiety is viewed as perceptions of abnormal body symptoms such as butterflies, sweating, shakiness, and increased heart rate (Martens et al., 1990) ${ }^{[4]}$. The Competitive State Anxiety Inventory-2 (CSAI-2: Martens, Burton, Vealey, Bump, and Smith, 1990) ${ }^{[4]}$ has been the measure of choice for most researchers of competition anxiety during the past decade.

The CSAI-2 also assesses self-confidence, which is characterised by positive expectations of success. The CSAI-2 has 27 items with nine items in each of three subscales: Cognitive Anxiety, Somatic Anxiety, and Self-confidence Athletes and theorists in human performance agree on the influence of psychological factors in the performance of motor skills, particularly at a high level of competition. As a result, an abundance of research has been dedicated to finding out not only how to prepare athletes mentally for high-pressure situations, but also what psychological factors are specifically determinants of performance. The use of selfreporting instruments that indicate specific psychological skills is widespread, especially in collegiate and professional athletics. Because of the comparable levels of physical abilities among top-tier athletes, coaches seek to understand which psychological factors separate the elite from the non-elite (Smith, Schutz, Smoll, \& Ptacek, 1995) ${ }^{[6]}$.

\section{Statistical Technique}

To determine the relationship between selected psychological variable and Volleyball performance Pearson's Product Moment Correlation was employed with the help of MS Excel.

\section{Material and Method}

\section{Selection of the subjects}

Forty subjects (batsmen) randomly were selected from the cricket during East Zone Cricket Tournamant (Men), organized by VBSP University, Jaunpur. The age ranged of the subject was $19-25$ years. 
Table 1: Measurement of the motor and SCAI -2 Variables

\begin{tabular}{|c|c|c|}
\hline Variables & Name of the test & Test (units) \\
\hline 1. Muscular Strength & SBJ & In Meters and centimetres \\
\hline 2. Muscular Endurance & Sit - Ups & Number of sit - ups in 60 seconds \\
\hline 3. $\quad$ Flexibility & Sit and reach & In centimetres \\
\hline 4. $\quad$ Speed & 50 yard dash & In seconds \\
\hline 5. Agility & Shuttle - run & In seconds \\
\hline 6. Reaction time & Nelson hand reaction & In seconds \\
\hline 7. $\quad$ Competitive Sports Anxiety & CASI -2 & Renin marten \\
\hline
\end{tabular}

\section{Cricket performance}

Cricket performance ability was measured by the subjective judgement, which were involved three cricket experts represented their university in east Zone Inter University Cricket Tournament. Five criteria prepared for the scoring of the batsmen playing ability after the discussion of the experts. Each criteria was maximum ten marks total fifty marks for a batsman. Added three scores which has been awarded by the threes experts and calculated average value was final score of a batsman.

1. Position of the batsmen before the facing the ball

2. Ball selection ability

3. Foot movements and strike the ball

4. Running between the wickets

5. Attitude towards a game

\section{Result}

Result of the was presented into the table form.

Table 2: Relationship of motor variables and SCAI -2 with the cricket performance

\begin{tabular}{|c|c|c|c|}
\hline S. No. & Variables & 'r' value & 'p' value \\
\hline 1. & Muscular Strength & $0.421^{*}$ & 0.02 \\
\hline 2. & Muscular Endurance & 0.213 & 0.23 \\
\hline 3. & Flexibility & $0.514^{*}$ & 0.01 \\
\hline 4. & Speed & -0.126 & 0.54 \\
\hline 5. & Agility & $0.431^{*}$ & 0.00 \\
\hline 6. & Reaction time & $-0.517^{*}$ & 0.04 \\
\hline 7. & Somatic Anxiety & $-0.458^{*}$ & 0.00 \\
\hline 8. & Cognitive Anxiety & $-0.539^{*}$ & 0.03 \\
\hline 9. & Self - confidence & $0.571^{*}$ & 0.00 \\
\hline
\end{tabular}

Significant level set at 0.05

Table 2 revealed the muscular strength $(0.421)$, flexibility (0.514), agility (0.431), reaction time (- 0.517), somatic anxiety (-0.458), cognitive anxiety (-0.539), self - confidence $(0.571)$ were significantly correlated with the cricket performance. Muscular endurance (0.213) and speed (-0.126) were not have the relationship with the cricket performance.

\section{Discussion on finding}

Result of the study have been revealed the muscular strength, flexibility, agility, reaction time, somatic anxiety, cognitive anxiety and self - confidence had correlated with cricket performance. Selected motor variable would be play a good role during the cricket game. Muscular strength needed during the various stroke and hard hit into the slog over of the game, flexibility might be reduce the chances of injury and foot movement of the player. Agility and reaction time play a key role during stroke. Optimum sports competitive anxiety play good role during the performance of the player. Self confidence also an integral part of the game which enhanced the player performance. Anxiety, even though it is a normal emotion experienced by many, if left unaddressed, can lead to more serious psychological disorders. Recognizing early signs and symptoms of anxiety typically fall on those professionals interacting with athletes on a daily basis. Clement $\mathrm{D}$ et al. (2013) ${ }^{[2]}$ and Meyer BB (2014) ${ }^{[5]}$ revealed the anxiety can influence athletes' cognitive appraisals, physiological arousals, and ultimately, performance in a range of performance related situations. Moreover, they should be mindful of how anxiety can transfer itself from one situation to another, and how this may vary depending on the athlete in question. It is also important to remember our role as part of a holistic, inter-professional team.

\section{Conclusion}

It had concluded on the basis of result somatic anxiety could influence the muscular activities, therefore, muscular strength, endurance and flexibility of the cricketers might be reduced. Cognitive anxiety related to brain, it may influence the reaction time of the cricketers. Gould and et al. (1995) ${ }^{[3]}$ reported that athletes which use mental skills can concentrate better and have higher self-confidence. Thus, it seems that different mental skills have positive effects on the performance of athletes and reduce anxiety before a competition.

\section{References}

1. Brewer BW, Redmond C. Psychology of Sport Injury. Champaign, IL: Human Kinetics, 2016.

2. Clement D, Arvinen-Barrow M. Sport medicine team influences in psychological rehabilitation: a multidisciplinary approach. In: Arvinen-Barrow $\mathrm{M}$, Walker N, editors. The Psychology of Sport Injury and Rehabilitation. Abingdon: Routledge, 2013, 156-170.

3. Gould D, Weinberg R. Foundation of Sport and Exercises Psychology, Human Kinetics (chapter 17), 1995.

4. Martens R, Burton D, Vealey R, Bump L, 7 Smith D. The development of the Competitive State Anxiety Inventory2 (CSAI-2). In R. Martens, R.S., Vealey, \& Burton (Ed.), Competitive anxiety in sport. Champaign, IL: Human Kinetics, 1990, 117-190.

5. Meyer BB, Merkur A, Ebersole KT, Massey WV. The realities of working in elite sport. What they didn't teach you in graduate school. In: Lane AM, Godfrey RJ, Loosemore M, Whyte GP, editors. Applied Sport Science and Medicine: Case Studies from Practice. CreateSpace: Self-published, 2014, 137-142.

6. Smith RE, Schutz RW, Smoll FL, Ptacek JT. Development and validation of a multidimensional measure of sport-specific psychological skills: the Athletic Coping Skills Inventory-28. Journal of Sport and Exercise Psychology. 1995; 17:379-398. 